\title{
0 quadro normativo do fechamento de mina e a gestão de minas abandonadas no Brasil e no Estado de Minas Gerais
}

\section{Patrícia Rocha Maciel Fernandes ${ }^{1}$ e Hernani Mota de Lima $^{2}$}

\author{
${ }^{1}$ Universidade Federal de Ouro Preto. Programa de Pós-Graduação em Engenharia \\ Mineral. Campus Morro do Cruzeiro. Ouro Preto-MG, Brasil (CEP 35400-000). \\ E-mail: patricia.fernandes@aluno.ufop.edu.br. \\ ${ }^{2}$ Universidade Federal de Ouro Preto. Escola de Minas. Departamento de \\ Mineracao. Campus Morro do Cruzeiro. Ouro Preto-MG, Brasil (CEP 35400-000).
}

Resumo. Este artigo apresenta uma avaliação do quadro normativo do Brasil, mais especificamente do Estado de Minas Gerais, quanto ao fechamento de minas e a gestão de minas abandonadas, decorrentes de um fechamento prematuro ou mal planejado. Mina abandonada é uma mina que o processo de fechamento está incompleto ou ausente, com a atividade de extração mineral inativa, sem previsão de reinício da atividade, sem medidas de controle ou monitoramento ambiental implementadas, apresentando características de abandono. A consulta e a análise das principais leis ordinárias e as normas infralegais federais e estaduais, relativas ao meio ambiente e mineração constituíram a base para realização deste estudo, assim como a consulta a banco de dados de minas abandonadas e os processos ambientais do Estado de Minas de Gerais, com visitas às minas para vistoria in loco. 0 artigo aponta que embora as regulamentações sobre fechamento de mina no Brasil sejam recentes, ocorreram avanços, com o estabelecimento da etapa de fechamento de mina no novo decreto do Código de Minas, no ano de 2018 e a modernização da legislação sobre o tema no Estado de Minas Gerais, neste mesmo ano. Entretanto, o ordenamento legal não está sendo concretizado em uma política pública efetiva pelos órgãos competentes, com a inexistência de um programa para a inibição do surgimento de minas abandonadas ou acompanhamento das minas abandonadas já identificadas.

Palavras-chave: Fechamento de mina; Minas abandonadas; Regulamentação; Brasil; Minas Gerais.

Abstract. The regulatory framework for mine closure and
management of abandoned mines in Brazil and the State of
Minas Gerais. This article presents an assessment of the
regulatory framework in Brazil, specifically in the State of Minas
Gerais, related to mine closures and the management of
abandoned mines, resulting from a premature or poorly mine

Recebido $14 / 12 / 2020$

Aceito

$15 / 04 / 2021$

Disponível on line 26/04/2021

Publicado $30 / 04 / 2021$

Acesso aberto

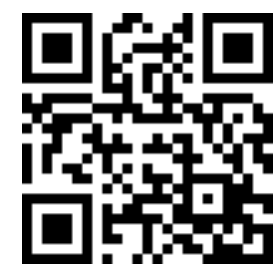

ORCID

(D) 0000-0001-5752-5682 Patrícia Rocha Maciel Fernandes

(D) 0000-0002-5595-4149 Hernani Mota de Lima

ISSN 2359-1412/RBGAS-2020-0175/2021/8/18/23/353

Rev. Bras. Gest. Amb. Sustent.

http://revista.ecogestaobrasil.net 
closure plan. Abandoned mine refers to a mine that the closure process is incomplete or absent, the mineral extraction is inactive, without estimating the activity return, control measures or environmental monitoring implemented and presenting abandonment characteristics. This study was based on searching and analysis of the main environment and mining ordinary laws and federal and state infralegal rules, as well as abandoned mine databases and processes of the environmental agency of Minas Gerais state, including inspection of mines. This article points out that although mine closure regulations in Brazil are recent, progresses has been made through the mine closure stage established in the new Brazilian Mining Code Decree in 2018 (Decree $n^{\circ}$ 9.406/2018) and the modernization of these subjects legislation, in the State of Minas Gerais, in the same year. Nevertheless, the legal order is not being implemented in an effective public policy by competent authorities, in the absence of a program to inhibit the emergence of abandoned mines or to monitor already identified abandoned mines.

Keywords: Mine closure; Abandoned mines; Regulation; Brazil; Minas Gerais.

\section{Introdução}

Apesar dos impactos positivos, principalmente econômicos, uma uma mina gera diversos impactos ambientais adversos, que devem ser mitigados e reparados pelo minerador. A evolução de todas as ações de recuperação das áreas degradadas pela operação de uma mina culmina no fechamento da mina, que engloba, ainda, a remoção das instalações, a implantação de medidas de segurança, a avaliação dos impactos do fechamento junto às comunidades vizinhas e a implantação de programas sociais (Sanchez et al., 2013).

O fechamento da mina pode assumir o caráter parcial ou total e ser permanente ou temporário (Flores e Lima, 2012), planejado ou prematuro (Sanchez, 2011). Quando o fechamento da mina ocorre de maneira não planejada, antes do estipulado em seu Plano de Aproveitamento Econômico (PAE), o minerador deve também se preocupar com as consequências ambientais e socioeconômicas, uma vez que elas são tão importantes quanto e, possivelmente, mais críticas do que aquelas decorrentes do fechamento planejado (Sanchez, 2011).

Os impactos de um abandono de mina são vários e incluem, desde a possível esterilização dos recursos remanescentes, a perda do valor da terra, a falta de proteção do solo, o surgimento de processos erosivos e assoreamento de corpos d'água, a contaminação do solo, de águas superficiais e subterrâneas, aos riscos à segurança para animais e a população do entorno e a redução de postos de trabalho, dentre outros (UNEP, 2001; Mhlongo e Amponsah-Dacosta, 2015; Bennett, 2016).

Por outro lado, as causas do abandono de minas são complexas e podem ser exclusivas de um local (Worrall et al., 2009; Unger et al., 2014; Unger, 2017). Entretanto, prioritariamente, o abandono decorre de falhas no planejamento do fechamento de mina ao longo da operação da mina, incluindo objetivos inalcançáveis; arcabouço legal e institucional insuficiente para exigir a implementação das ações de fechamento, em articulação com as comunidades impactadas; incapacidade do órgão regulador em exigir no licenciamento ambiental as ações de recuperação ambiental; motivos econômicos, 
principalmente relacionados a queda dos preços das commodities minerais e perda de mercado para determinados bens; subestimação dos custos e prazos de fechamento ou ausência de uma provisão para as etapas de fechamento .

A Portaria DNPM no 237/2001 (Brasil, 2001) estabelece normas reguladoras que tratam de aspectos gerais operacionais e administrativos de um processo mineral, incluindo diretrizes para o fechamento de minas. O Decreto no 9.406/2018 traz nova regulamentação para o Código Mineral de 1967 (Brasil, 1967, 2018) com alterações significativas para o setor mineral; estabelece o fechamento de mina como uma etapa do ciclo de vida de uma mina, assim como apresenta obrigações claras quanto à execução do Plano de Fechamento de Mina e à recuperação ambiental da área, antes da renúncia ao título minerário.

Minas Gerais é o único Estado brasileiro a possuir legislação específica para o fechamento de mina, incluindo diretrizes para as minas abandonadas (Minas Gerais, 2008, 2018). Para encerrar suas atividades o minerador deve apresentar um Plano de Recuperação de Áreas Degradadas (PRAD) ou um Plano Ambiental de Fechamento de Mina (PAFEM), a depender do porte e potencial de impacto ambiental da mina; e realizar uma reunião pública no caso de significativo impacto socioeconômico decorrente do fechamento. Ao final da implementação das ações, o órgão ambiental é responsável por emitir "Declaração de Recuperação Ambiental", atestando o efetivo cumprimento dos planos.

Vários países têm desenvolvido programas, em paralelo com a criação de instrumentos legais, para o cadastramento e reabilitação de minas abandonadas, de forma a minimizar os passivos ambientais e sociais resultado do abandono dessas áreas (SERNAGEOMIN, 2007; Gonzáles, 2008; Oblasser e Chaparro, 2008; ASGA, 2009; MCMPR e MCA, 2010; DGEG, 2011; Araujo, 2015; FEAM, 2016; Sotomayor Cabrera, 2016; APEC, 2018). APEC (2018) relaciona quatro elementos principais de uma política para minas abandonadas: o inventário das áreas; o estabelecimento de critérios de priorização; a determinação dos custos de recuperação/remediação; e o financiamento da recuperação/remediação. Por sua vez, MCMPR e MCA (2010) apontam cinco, incluindo o inventário e gerenciamento dos dados; a compreensão das responsabilidades e riscos associados; os relatórios de desempenho das intervenções; a padronização de processos e de metodologias; e o compartilhamento de obrigações entre os órgãos.

Dados de diversos países apontam para a multiplicação de passivos relacionados às minas abandonadas. Nos Estados Unidos, estimam-se mais de 600 mil minas abandonadas (Araujo, 2015). No Canadá, de 2002 a 2015, foi despendido mais de 1 bilhão de dólares canadenses na recuperação de minas órfãs e abandonadas (NOAMI, 2015) e o número estimado é de cerca de 10.100. Na Austrália, foram estimadas 32.600 minas abandonadas e, no Japão, 5.550. No Chile, cerca de 1.470 minas já foram mapeadas, em situação de abandono ou paralisação (SERNAGEOMIN, 2020). No Peru, foram cadastradas 8.854 minas abandonadas (Sotomayor Cabrera, 2016). Na África do Sul, um inventário de 2009 levantou 5.906 minas abandonadas (AGSA, 2009). Em Portugal, até 2015, ocorreram intervenções em 95 minas abandonadas, com um custo de aproximadamente 89 milhões de euros (Carvalho et al., 2016). Entretanto, o mapeamento e a qualidade dos dados sobre minas abandonadas em diversos países é considerado de ruim a médio (Worrall et al., 2009).

No Brasil há vários casos de minas órfãs e abandonadas, das quais não se conhece o titular (Taveira, 2013). Como, ao encerrar uma empresa, não é preciso obter o "nada consta" nos órgãos ambientais, o custo por problemas socioambientais acaba recaindo sobre o governo e a sociedade. Em Minas Gerais, um inventário do órgão ambiental sobre minas paralisadas e abandonadas contabilizou 169 em situação de abandono (Feam, 2016). 
Este artigo apresenta os regulamentos relativos ao fechamento de mina existentes no Brasil, e avalia a eficiência da abordagem utilizada pelos órgãos ambientais e de gestão da atividade minerária e dos recursos minerais, tomando como estudo de caso o Estado de Minas Gerais, a gestão do fechamento de mina para minas em operação e das minas abandonadas.

\section{Materiais e métodos}

A consulta e a análise das principais leis ordinárias e as normas infralegais federais, relativas ao meio ambiente e mineração constituíram a base para realização deste estudo. As leis e normas consultadas incluíram, em nível federal:

A. A Constituição Federal de 1988 (Brasil, 1988).

B. A Legislação Federal Ambiental: Lei no 6.938/1981 - Política Nacional do Meio Ambiente (Brasil, 1981); o Decreto no 97.632/1989 (Brasil, 1989a), e a Lei no 9.605/1998, Lei de Crimes Ambientais (Brasil, 1998).

C. O Código de Minas de 1967 (Brasil, 1967), a Lei no 7.805/1989 (Brasil, 1989), a Portaria no 237/2001 (Brasil, 2001) e as Normas Reguladoras (Brasil, 2001); e o Decreto no 9.406/2018 (Brasil, 2018).

Em nível estadual, foram avaliadas as duas normas que regulamentam o fechamento de mina no Estado de Minas Gerais:

A. A Deliberação Normativa COPAM no 127/2008 (Minas Gerais, 2008).

B. A Deliberação Normativa COPAM no 220/2018 (Minas Gerais, 2018).

Uma pesquisa bibliográfica dirigida essencialmente para a literatura disponível sobre os vários aspectos envolvidos no fechamento de mina, gestão de passivos ambientais minerários e minas abandonadas, incluindo regulamentos internacionais e boas práticas foi realizada. A partir desse embasamento teórico realizou-se a análise e discussão sobre eficiência da abordagem utilizada pela Fundação Estadual do Meio Ambiente e pela Agência Nacional de Mineração quanto à gestão do fechamento de mina para minas em operação e das minas abandonadas.

\section{Resultados e discussão}

\section{Panorama nacional sobre fechamento de mina e gestão de minas abandonadas}

Desde o início da exploração mineral no Brasil, a política de exploração focou no desenvolvimento econômico, mas em descompasso com a proteção ambiental, dado a ausência de normas que tratassem de obrigações quando do fechamento das minas ou de regras para a recuperação e mitigação de impactos e danos causados (Sampaio et al., 2019). Até 1980, a mineração concentrava sua preocupação no aproveitamento dos recursos minerais e no seu fomento.

A Política Nacional do Meio Ambiente (PNMA), instituída pela Lei no 6.938/1981, alterou essa cultura ao introduzir no ordenamento jurídico brasileiro, importantes instrumentos e obrigações para a proteção ambiental, com a previsão expressa da obrigatoriedade de recuperação das áreas degradadas, como um dos seus princípios (art. $2^{\circ}$, inciso VII). A PNMA, no art. 4º, do inciso VII, consagrou o princípio do poluidor-pagador ao impor ao poluidor e ao predador a obrigação de recuperar e/ou indenizar os danos causados e, ao usuário, da contribuição pela utilização de recursos ambientais com fins econômicos. Por fim, previu a necessidade da avaliação de impacto ambiental e do 
processo de licenciamento ambiental de empreendimentos que impactam o meio ambiente (art. 9o, incisos III e IV) (Brasil, 1981).

A Constituição Brasileira de 1988, recepciona de forma integral os dispositivos da PNMA, com um capítulo exclusivo ao meio ambiente e sobre as obrigações do poluidorpagador, incluindo o minerador, à apresentação de estudos ambientais e à reparação de danos causados ao meio ambiente, com a devida recuperação das áreas degradadas. Conforme o art. $225, \S 2^{\circ}$, o poluidor deve reparar os danos causados ao meio ambiente e a terceiros, que decorram de sua atividade, bem como, especificamente, o daquele que explore recursos minerais. A recuperação do meio ambiente degradado deve ser de acordo com solução técnica exigida pelo órgão público competente, na forma da lei (Brasil, 1988).

De acordo Constituição Federal, enquanto compete à União legislar sobre as jazidas, as minas e sobre outros recursos minerais, compete, concorrentemente, à União, aos Estados e ao Distrito Federal legislar sobre a defesa do solo e dos recursos naturais, proteção do meio ambiente e controle da poluição, cabendo aos municípios a competência para suplementar a legislação federal e estadual quando couber. Compete, portanto, aos órgãos ambientais, a aprovação da atividade minerária, mas também as medidas para recuperação do meio ambiente degradado, incluindo o uso futuro (Brasil, 1988; Flores e Lima, 2012).

0 abandono de uma área minerada sem recuperação produz consequências nas esferas administrativa, penal e cível, pois, conforme preceitua o $\S 3^{\circ}$, do art. 225 , da Constituição de 1988: "as condutas e atividades consideradas lesivas ao meio ambiente sujeitarão os infratores, pessoas físicas ou jurídicas, a sanções penais e administrativas, independentemente da obrigação de reparar os danos causados".

Quanto à reparação de dano ambiental e recuperação das áreas degradadas pela mineração, o Decreto no 97.632/1989 (Brasil, 1989a), trouxe pela primeira vez um posicionamento normativo sobre o fechamento de minas no país, determinando que as minerações devem apresentar Plano de Recuperação de Área Degradada (PRAD) quando do requerimento do licenciamento ambiental, com objetivo principal de retorno do sítio degradado a uma forma de utilização, de acordo com um plano preestabelecido para o uso do solo, visando a obtenção de uma estabilidade do meio ambiente. Com base nesse Plano, o órgão ambiental toma ciência prévia de quais as medidas mitigadoras, reparatórias e/ou compensatórias serão adotadas para a recuperação das áreas degradadas ao longo da vida de uma mina.

A Lei no 9.605/1998, a Lei de Crimes Ambientais (Brasil, 1998), tipifica que o abandono de uma área minerada sem recuperação ambiental configura, em tese, tipo penal descrito no art. 55. Ou seja, quem executar pesquisa, lavra ou extração de recursos minerais sem a competente autorização, permissão, concessão ou licença, ou em desacordo com a obtida, confere pena de detenção, de seis meses a um ano, e multa. Esta pena é aplicada, também, para quem deixa de recuperar a área pesquisada ou explorada, nos termos da autorização, permissão, licença, concessão ou determinação do órgão competente.

O planejamento e autorização da exploração mineral e do aproveitamento dos recursos minerais são definidos principalmente no Código de Minas, de seus regulamentos e das Normas Reguladoras de Mineração (NRM), promulgados pelo Ministério de Minas e Energia e pela Agência Nacional de Mineração (ANM). Os Códigos de Minas de 1934 e 1940, assim como o Código de Mineração de 1967 foram promulgados em épocas em que os preceitos de proteção ambiental ainda não integravam as preocupações constitucionais da maioria das nações, não dispensando atenção as questões relacionadas ao fechamento de mina (Brasil, 1934, 1940; Flores e Lima, 2012).

As discussões sobre fechamento de mina são recentes, mas tem se mostrado crescente nas duas últimas décadas (Sanchez et al., 2013). No campo normativo, foram instituídas normas infralegais, que regulamentam as etapas de paralisação temporária e 
fechamento de mina, por meio de Normas Reguladoras de Mineração (NRM). A Portaria no $237 / 2001$ (Brasil, 2001) estabeleceu normas reguladoras que tratam de aspectos gerais operacionais e administrativos do processo mineral. Em relação aos aspectos ambientais foram publicadas as NRM no 19, NRM no 20 e NRM no 21 (Brasil, 2011). A NRM no 20 trata da suspensão, fechamento e retomada das operações mineiras, exigindo a execução de um Plano de Fechamento de Mina e a recuperação ambiental.

Apesar da publicação das normas reguladoras da mineração, o Código de Mineração de 1967 (Brasil, 1967), não trazia qualquer previsão normativa sobre o fechamento de mina, até a sua nova regulamentação, por meio do Decreto no 9.406/2018 (Brasil, 2018). 0 novo regulamento apresenta exigências ambientais mais rígidas, estabelece o fechamento de mina como uma etapa da vida da mineração e a responsabilidade pela recuperação das áreas degradadas. Anteriormente, o conceito era tratado apenas em norma reguladora do órgão gestor dos direitos minerários (Brasil, 2001). A partir da publicação do decreto, o fechamento de mina passa a fazer parte do ciclo da vida da mina e as obrigações do titular ficam explícitas, incluindo a desmobilização das estruturas, a recuperação de áreas degradadas e o monitoramento.

De acordo com Código de Mineração e o novo regulamento (Brasil, 1967, 2018) é obrigação do minerador evitar a poluição do ar e da água e manter a mina em bom estado no caso de suspensão temporária, de modo a permitir a retomada das operações. 0 novo regulamento avança na tentativa de concretizar os preceitos protetivos do meio ambiente e estabelece que o título minerário será recusado ou revogado se a atividade minerária for considerada prejudicial ao bem público ou comprometer interesses que superem a utilidade da exploração industrial do recurso mineral.

O Código de Mineração (Brasil, 1967) e a NRM no 20 consideram como suspensas as minas sem atividade minerária por um período maior que seis meses, utilizando o termo "suspensão temporária das atividades mineiras". Na NRM № 20, a suspensão, o fechamento de mina e a retomada das operações mineiras não podem ser efetivadas sem a prévia comunicação e autorização do poder público. Em caso de suspensão temporária das atividades de lavra, a empresa após comunicação prévia, deve apresentar pleito ao Ministro de Estado de Minas e Energia em requerimento justificado caracterizando o período de suspensão pretendido, devidamente acompanhado de instrumentos comprobatórios, incluindo, planos e medidas que serão executados durante a suspensão, visando evitar acidentes com pessoas e animais e proteger o meio ambiente.

Entretanto, o Decreto no 9.406/2018 estabeleceu novo rito para que o minerador paralise suas atividades. A partir da comunicação prevista na NRM 20, o titular pode interromper suas atividades enquanto o requerimento de suspensão temporária de lavra estiver pendente de decisão da ANM, que só poderá ser concedido após vistoria no local. Caso a ANM não conceda a suspensão temporária, será estabelecido prazo para o reinício das operações e aplicado de sanções, caso necessário.

Ou seja, a partir de novo entendimento da regulamentação do Código Mineral (Brasil, 2018), o minerador não depende de avaliação e autorização governamental para interromper suas atividades, sendo necessário, entretanto, uma avaliação da ANM para a validar e ratificar o pedido de suspensão temporária. Todavia, a norma é omissa, em relação aos prazos para análise desses pedidos e de como devem ser tratados os casos que o pedido de suspensão não é autorizado e o empreendedor não possuir condições de retorno da lavra, no prazo estipulado, podendo ocasionar no fechamento prematuro e abandono da área.

Resende e Lima (2009) analisaram as concessões de lavra outorgadas no estado de Minas Gerais, quanto ao percentual de minas em suspensão de lavra. Das 1.739 concessões de lavra no estado, 234 minas encontravam-se com suspensão temporária de lavra. Entretanto, não havia informações sobre as atividades de reabilitação, monitoramento e reabilitação no extinto DNPM ou órgão ambiental, o que infere um potencial passivo 
decorrente da suspensão, e que independente, da reserva remanescente e do valor do bem mineral, pode inviabilizar uma retomada das operações. Tal fato, chama atenção para o acréscimo do número de minas abandonadas e a necessidade da intervenção do poder judiciário para lograr o devido fechamento.

Centeno (2017), ao analisar dados do Estado de Santa Catarina, reporta a inexistência, no DNPM, de uma metodologia para análise de requerimentos de suspensão temporária de mina. Tal fato demonstra a dificuldade em se implementar por meio de políticas públicas, as obrigações previstas na legislação federal.

Embora não exista um prazo máximo para suspensão temporária da lavra (Brasil, 1967), aprovar o prazo de suspensão de uma mina é obrigação da ANM. Entretanto, não há previsão de multas ou taxas para uma área que esteja improdutiva, o que acaba estimulando as empresas mineradoras a ficarem com áreas sem produção, muitas vezes para garantir exclusividade do material na região ou para futuras negociações ou a própria retomada da atividade.

De acordo com a NRM no 20, a retomada de uma mina só poderá ocorrer após manifestação favorável da ANM do Projeto de Retomada das Operações Mineirais, mediante comunicação prévia junto à ANM, dentro do prazo de validade da suspensão autorizada. O Decreto no 9.406/2018 não modifica o exposto na NRM no 20 e, tampouco, não estabelece diretrizes procedimentais aos órgãos públicos para acompanhamento das etapas de suspensão e retomada das operações.

Quanto ao fechamento definitivo, o Decreto no 9.406/2018 exige do minerador a apresentação de um Plano de Fechamento de Mina (PFM) juntamente com a entrega do Plano de Aproveitamento Econômico (PAE), antes da outorga do título de lavra no regime de concessão de lavra, seguindo as diretrizes da NRM no 20. O PFM, que deve ser atualizado periodicamente, deve conter informações mínimas como: relatório dos trabalhos efetuados, caracterização das reservas remanescentes, plano de desmobilização das estruturas, projetos para a recuperação ambiental, plano de controle da poluição ambiental, programa de monitoramento ambiental, aptidão e intenção de uso futuro da área, relatório das condições de saúde ocupacional dos trabalhadores.

Numa análise de processos minerários da Superintendência do DNPM em Minas Gerais, Resende et al. (2010) identificaram o não cumprimento das diretrizes do PFM por parte dos mineradores e a não fiscalização por parte do DNPM. Os autores identificaram a ausência de planos de fechamento em 30 PAEs de minas de ferro, protocolados após a publicação da NRM no 20.

Mesmo que o Decreto no 9.406/2018 estabeleça o momento de apresentação do Plano de Fechamento de Mina, a normativa federal não traz diretrizes claras no que se refere aos prazos para análise e manifestação da ANM e como o acompanhamento da implementação do PFM. Tampouco, este decreto, não explicita a articulação com as agências ambientais para uma análise integrada e compartilhamento de informações.

No novo regulamento, a renúncia total ou parcial da concessão de lavra deverá ser precedida de relatório dos trabalhos efetuados e do estado da mina e de suas possibilidades futuras, conforme previsto na NRM no 20. Portanto, a renúncia ao título, com o consequente encerramento das obrigações junto ao governo federal, está condicionada a execução do PFM.

Para os regimes distintos da concessão (licenciamento e lavra garimpeira), não existe previsão para a apresentação do Plano de Fechamento no Decreto no 9.406/2018 (Brasil, 2018). Estes regimes podem trazer grandes impactos ambientais como os garimpos ou pedreiras de rocha ornamental, com paredões de mais de $20 \mathrm{~m}$. Ou seja, para estes regimes não existe nenhum planejamento para o fechamento da mina, o que eleva o risco de que eventual fechamento de mina não seja realizado de forma tempestiva e planejada, ou ainda, que sequer haja o fechamento da mina. 
O Código Mineral, em seus regulamentos, ou a NRM no 20, não tratam do fechamento prematuro de mina . Caso o fechamento seja realizado antes da data prevista por algum motivo adverso à exaustão das reservas, o procedimento adotado é o mesmo para o fechamento definitivo, não havendo distinção ou critérios quanto à especificidade da situação. Sanchéz (2011) o fechamento prematuro deve ser considerado na elaboração do plano de fechamento. 0 autor ressalta dificuldades adicionais decorrentes do fechamento prematuro, como o curto período para implementação de programas de desativação, a necessidade de se adiantarem medidas de reabilitação e os problemas socioeconômicos para a comunidade local. A ausência de um plano de fechamento pode trazer consequências negativas para a comunidade, para o ambiente e para a própria empresa, no caso de uma interrupção prematura das operações de uma mina.

Quando caracterizado o abandono de uma mina, o Código de Mineração, no art. 65, traz, em alguns casos, a possibilidade de caducidade do título de lavra concedido à empresa detentora do título (Brasil, 1967). E, o novo regulamento do Código Mineral estabelece sanções relativas à não execução e conclusão do plano de fechamento da mina, com multa no valor de $\mathrm{R} \$ 3.364,32$ (três mil, trezentos e sessenta e quatro reais e trinta e dois centavos) e no caso de abandono da mina ou jazida, o minerador é passível de autuação, no valor de $\mathrm{R} \$ 3.293,90$ (três mil, duzentos e noventa e três reais e noventa centavos) e caducidade do título.

Ao fixar valores baixos, as multas aplicáveis pela ANM podem ser adequadas para um pequeno minerador, mas são materialmente insignificantes se comparadas ao prejuízo potencial decorrente de um fechamento inadequado ou do abandono de uma mina de médio a grande porte. Além disso, a Lei Federal no 7.805/1989 que altera o Decreto-Lei no 227/1967 (Brasil, 1967, 1989), apresenta a possibilidade de suspensão temporária ou definitiva de trabalhos de pesquisa ou lavra que causarem danos ao meio ambiente, de acordo com parecer do órgão ambiental competente.

O Plano Nacional de Mineração 2030 (Brasil, 2011) é uma ferramenta que busca nortear as políticas de médio e de longo prazo para o setor mineral, alicerçada no desenvolvimento sustentável. Este Plano afirma que o marco legal para o fechamento de minas no Brasil está embasado na Constituição Federal de 1988, no Decreto no 97.632/1989, e na NRM no 20. Entretanto, a Constituição Federal e o Decreto no 97.632/1989 não foram suficientes, uma vez que não consideram a complexidade do tema e os impactos socioeconômicos da suspensão temporária e não disciplinam adequadamente como deve ser o monitoramento das variáveis de controle ambiental.

\section{Panorama Estadual (Estado de Minas Gerais) sobre fechamento de mina e gestão de minas abandonadas}

Desde 2008, Minas Gerais é o único Estado brasileiro a possuir legislação ambiental específica para a etapa de fechamento de mina e a paralisação temporária da atividade minerária. Trata-se da Deliberação Normativa COPAM no 127/2008 (Minas Gerais, 2008), revogada e substituída em 2018, pela Deliberação Normativa COPAM no 220/2018 (Minas Gerais, 2018a).

A legislação estadual estabelece os estudos e ações que devem ser executados pelo minerador para o fechamento da mina e também durante a suspensão temporária das atividades minerárias, abordando também obrigações para as minas abandonadas. 0 fechamento de mina é entendido como um processo que abrange toda a vida da mina, desde a fase dos estudos de viabilidade econômica até o encerramento da atividade minerária, incluindo a desativação, a reabilitação e o uso futuro da área degradada.

A Deliberação Normativa COPAM no 127/2008 estabeleceu a etapa de fechamento de mina como um processo de regularização junto ao órgão ambiental, exigindo que qualquer mineração ao encerrar suas atividades deveria executar um Plano Ambiental de Fechamento de Mina (PAFEM), a ser apresentado com antecedência mínima de dois anos 
do encerramento das atividades com a realização de reunião pública com a comunidade impactada. Um dos principais ganhos advindos desta deliberação é a vinculação dos impactos sociais com os ambientais, resultantes do encerramento da atividade minerária em uma determinada região, uma vez que prevê a realocação de trabalhadores e o desenvolvimento de projetos sociais com vistas a minimizar a dependência da população do entorno.

A Deliberação Normativa COPAM no 127/2008 trouxe avanço na normatização e acompanhamento da etapa de fechamento de mina no Estado de Minas Gerais ao incluir um termo de referência para elaboração de um relatório de situação para as minas paralisadas e a previsão de atualização periódica das informações pertinentes a essas minas. As lacunas observadas na DN, por outro lado, geraram falta de padronização das informações apresentadas nos relatórios e ausência de informações atualizadas, prejudicando o acompanhamento por parte do órgão ambiental.

A maioria das minas que paralisaram suas atividades na vigência da Deliberação Normativa COPAM no 127/2008 não apresentou o Relatório Circunstanciado de Paralisação de Atividade Minerária (FEAM, 2016). O órgão ambiental, apenas tomou conhecimento da situação por meio de vistorias, denúncias, por informações repassadas por otros órgãos públicos, como a ANM, Ministério Público Estadual, Prefeituras Municipais e Polícia Militar Ambiental.

A Deliberação Normativa COPAM no 127/2008 teve baixa adesão e efetividade, quanto ao fechamento de mina, junto ao setor minerário. Durante vigência da Deliberação Normativa COPAM no $127 / 2008$, apenas dois PAFEMs foram protocolados e analisados pelo órgão ambiental, sendo relativos a empreendimentos de médio porte, da tipologia de bauxita. Quanto à exigência que as minas abandonadas apresentassem um PAFEM, a Deliberação Normativa COPAM no 127/2008 mostrou-se contraditória e pouco aplicável, sem nenhuma formalização deste plano junto ao órgão ambiental.

A Deliberação Normativa COPAM no 220/2018, apresentou definições de grande importância para o fechamento e gestão dos passivos da mineração em Minas Gerais, como o conceito de minas paralisadas, Plano de Recuperação de Áreas Degradadas e Relatório de Paralisação de Atividade Minerária e reformulou importantes conceitos, como o de "minas abandonadas", que diz respeito a: "empreendimento com a atividade de extração mineral inativa, sem previsão de reinício da atividade, sem medidas de controle ou monitoramento ambiental, caracterizando o abandono do empreendimento, no qual o processo de fechamento está incompleto ou ausente".

A criação de um termo de referência para elaboração do Relatório de Paralisação da Atividade Minerária, que deve ser acompanhado de Anotação de Responsabilidade Técnica e ser atualizado pelo empreendedor no máximo a cada dois anos ou quando houver alterações nas ações implementadas, foi uma mudança substancial relativa às minas paralisadas. Este relatório deve ser protocolado, em um prazo máximo de 180 dias do início da paralisação, sendo que a retomada da atividade deve ser comunicada, até 30 dias após o retorno da operação. Esta mudança buscou melhorar a qualidade dos relatórios apresentados e o diagnóstico das áreas. Além disso, com a exigência da atualização bianual das informações durante a paralisação da mina, o órgão ambiental pretende inibir o abandono de minas.

Segundo a Deliberação Normativa COPAM no 220/2018, a paralisação da atividade minerária não altera o prazo da validade da licença ambiental vigente, o cumprimento das obrigações e os procedimentos relacionados ao licenciamento ambiental. Na prática, uma mina que permanece paralisada por um período maior que a validade de sua licença ambiental, no retorno da operação da mina, terá que obter uma nova licença. A solicitação de um documento que detalhe as ações durante a paralisação da mina é importante, pois grande parte dos empreendimentos que solicitam fechamento temporário das atividades

Rev. Bras. Gest. Amb. Sustent., 2021, vol. 8, n. 18, p. 353-370. 
de lavra (suspensão) não retomam as atividades, sendo assim o primeiro passo para o fechamento prematuro ou abandono de uma mina (Sanches et al., 2013; Centeno, 2017).

Em relação ao fechamento de minas ativas, a Deliberação Normativa COPAM no $220 / 2018$ estabelece que o plano a ser apresentado é função do porte do empreendimento, sendo um PRAD para empreendimentos de pequeno e médio porte e um PAFEM para os de grande porte. A critério do órgão ambiental, o PAFEM também poderá ser solicitado aos empreendimentos de pequeno e médio porte, em substituição ao PRAD.

Com foco na avaliação e mitigação dos impactos nos meios físico e biótico e na recuperação ambiental, o PRAD deve ser protocolado seis meses antes do encerramento da atividade. O PAFEM deve ser protocolado com antecedência mínima de dois anos da data prevista para o encerramento das atividades. O PAFEM deve contemplar a reavaliação dos principais impactos socioambientais causados pela mineração durante sua operação, a identificação dos impactos pós-fechamento, a definição das ações que serão executadas após o fechamento da mina com o respectivo monitoramento, em função do uso futuro previsto para a área. As ações e etapas do fechamento de grandes minas devem ser divulgadas à comunidade via reunião pública, com ênfase nos aspectos ambientais, sociais e propostas de uso futuro da área, para que a comunidade possa participar do processo decisório, apresentando sugestões e opiniões.

Esta diferenciação no tipo de plano a ser apresentado pelo minerador é fundamental para a adesão do setor no cumprimento das exigências do órgão regulador. A apresentação de um plano robusto que analise com profundidade os aspectos socioeconômicos é necessária para grandes empreendimentos, que mobilizam centenas de pessoas para a execução dos seus trabalhos, mas faz pouco sentido para empreendimentos pequenos que mobilizam uma dezena de pessoas e os impactos se restringem aos meios físicos e bióticos. Além disso, a elaboração de estudos socioambientais é extremamente onerosa, o que pode comprometer a disponibilidade financeira para a recuperação ambiental das áreas degradadas nos pequenos empreendimentos.

Mesmo que a legislação mineira preconize que o fechamento de mina é um processo que abrange toda a vida da mina, o momento de apresentação dos estudos específicos para o fechamento da mina e diálogo com a sociedade, próximo ao encerramento das atividades, contrapõe às boas práticas e legislações internacionais, que afirmam que um programa de fechamento mesmo que conceitual deve ser apresentado antes da obtenção das licenças ambiental e mineral (Sanchez, 2011; Flôres e Lima, 2012; Neri, 2013). Ademais, o envolvimento das partes interessadas no fechamento deve ser precoce, regular e transparente (McCullough, 2016).

As minas em fase de pesquisa mineral que tenham seus relatórios de pesquisa reprovados pela ANM e tenham gerado impactos ambientais devem implementar um PRAD. Esta exigência foi imposta a partir da constatação que grande parte das áreas classificadas como abandonadas ou que se encontram paralisadas sem os devidos controles se enquadram nessa situação (FEAM, 2016). Ou seja, são "minas" que não tiveram a concessão de lavra. Não existem diretrizes no regulamento estadual para os casos em que o minerador apresente um relatório de pesquisa negativo, ou seja, quando não foi possível comprovar ocorrências minerais economicamente viáveis, mas que podem também ter gerado impacto ambiental.

A legislação mineira estabelece prazos para que o órgão ambiental se manifeste sobre os estudos protocolados pelo minerador, sendo definido o prazo máximo de 12 meses para o PAFEM. E, para as minas de pequeno porte, fica estabelecido que caso não ocorra manifestação no prazo de seis meses, o PRAD pode ser executado, sem prejuízo de modificações posteriores.

Para que o processo de fechamento seja considerado concluído, o órgão ambiental deverá acompanhar a implementação das ações por meio de vistorias e avaliações de relatórios e emitir uma "Declaração de Recuperação Ambiental", atestando o cumprimento 
de todos os objetivos definidos na ocasião da aprovação do PAFEM ou do PRAD. Esta etapa se assemelha a etapa de "transferência de custódia", ou seja, a aprovação formal pela autoridade reguladora pertinente indicando que os critérios de fechamento para a mina foram atingidos de forma satisfatória para essa autoridade (ICMM, 2008).

A boa prática preconiza que o sucesso da transferência de custódia, está calcada nas clareza das relações entre a empresa e a autoridade reguladora, e que as medidas tomadas sejam mensuráveis e auditáveis. Entretanto, algumas minas, "em fechamento", necessitam monitoramento por longo prazo. A Deliberação neste sentido é omissa, visto que não estabeleceu nenhuma diretriz para as ações pós-fechamento ou um período mínimo de monitoramento, ficando a cargo do analista ambiental estabelecer estas ações e prazos, caso a caso. Ou seja, a discricionariedade do técnico pode gerar incertezas na análise dos processos. Por mais que cada mina possua particularidades, é fundamental que o poder público estabeleça orientações, prazos e padrões mínimos, para a formalização da transferência de custódia/novo uso.

A legislação de Minas Gerais, em relação às minas abandonadas, estabelece apenas uma diretriz, que diz respeito à obrigatoriedade do responsável por este local em executar um PRAD, para fins de fechamento e recuperação ambiental da mina. Anteriormente, a lei estadual (Minas Gerais, 2008) exigia a recuperação destas minas por meio da execução do PAFEM. Esta obrigação se mostrou pouco efetiva, uma vez que na maioria dos casos, em minas abandonadas o minerador já se eximiu da responsabilidade de executar os controles ambientais, sendo pouco efetiva as diretrizes estabelecidas pelo órgão ambiental. A nova legislação inseriu a flexibilização no processo de recuperação de áreas abandonadas ao desincumbir o empreendedor de apresentar o PAFEM, substituindo-o pela obrigatoriedade na elaboração do PRAD.

Em relação às sanções, na legislação estadual não existe uma tipificação específica sobre a não execução das ações de fechamento da mina ou abandono da área. 0 órgão ambiental utiliza a infração de descumprimento de legislação específica, sendo que os valores variam do valor de $\mathrm{R} \$ 927,90$ e $\mathrm{R} \$ 100.213,20$, conforme o porte do empreendimento (Minas Gerais, 2018b). Em face dos baixos valores das multas e da insuficiência de sanções efetivas, assim como na esfera federal, existe o risco da não realização de procedimentos relativos ao necessário fechamento de mina, podendo ser mais vantajoso economicamente ao minerador abandonar a mina, mesmo sob o risco de sanção.

Em paralelo a regulamentação para o fechamento de mina, o Estado de Minas Gerais publicou em 2016, o I Cadastro de Minas Paralisadas e Abandonadas do Estado de Minas Gerais (FEAM, 2016), com uma metodologia para inventariar e classificar minas paralisadas e abandonadas quanto ao potencial risco ambiental. Um total de 400 minas paralisadas foram cadastradas (Figura 1).

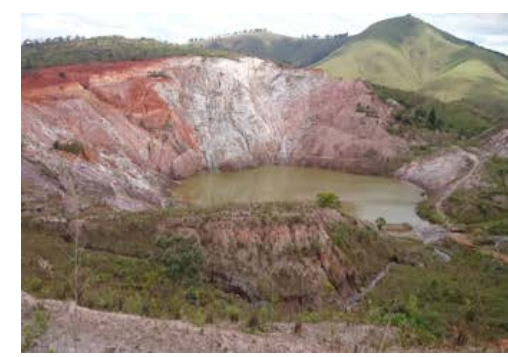

(a) Topázio Imperial

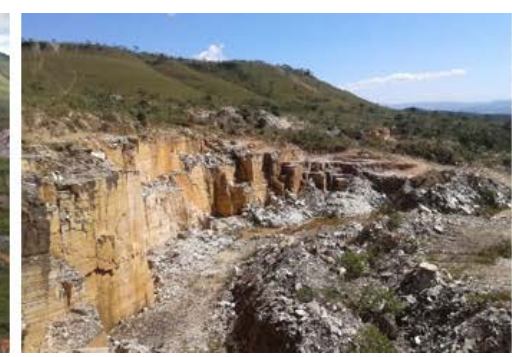

(b) Quartzito

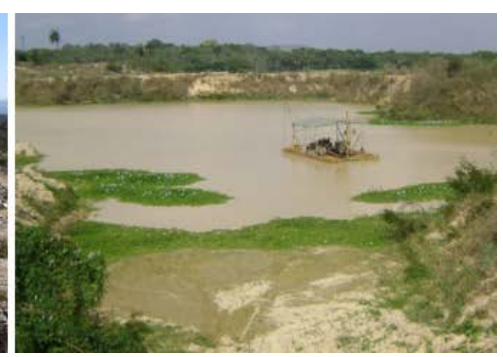

(c) Areia

Figura 1. Minas abandonadas no Estado de Minas Gerais, por tipologia minerária. 
De 2016 a 2020, o cadastro de minas abandonadas não foi atualizado e o órgão ambiental, tampouco, apresentou as ações que vêm sendo tomadas nas minas já cadastradas, seja em relação ao acompanhamento da execução de ações de recuperação ou retomada das atividades, bem como a autuação de empreendedores que não adotaram as medidas exigidas. As melhores práticas e regulamentos internacionais (MCMPR e MCA, 2010; NOAMI, 2010; Unger, 2017; McCullough, 2016; APEC, 2018) preconizam que o órgão ambiental ou gestor de recursos minerários deve manter um cadastro atualizado das minas paralisadas e abandonadas, apontando a evolução das ações visando a retomada das atividades ou o seu encerramento com a respectiva recuperação ambiental, conforme novo uso acordado para a área.

A falta de atualização das informações relativas às minas paralisadas e abandonadas, contrapõe a conclusão do I Cadastro, que afirmou:

O Cadastro aumentará a capacidade da Fundação Estadual do Meio Ambiente (FEAM) de identificar, analisar e gerenciar a situação de empreendimentos minerários nessas situações. A FEAM pretende continuar o mapeamento das minas em situação irregular, visando identificar situações que configurem risco ao meio ambiente e à saúde humana. Além disso, o órgão ambiental, em conjunto com outros órgãos públicos, deve incrementar seu papel regulamentador e fiscalizador, aumentando sua presença em regiões mineradoras (FEAM, 2016).

Apesar das melhorias trazidas pela Deliberação Normativa COPAM no 220/2018, um dos principais instrumentos verificados nos regimentos e boas práticas internacionais (Taveira, 2003; Miller, 2005; ICMM, 2006; Poveda, 2007; Almeida e Lima, 2008; Sànches et al., 2013; Neri, 2013) a exigência de garantia financeira para assegurar recursos para a etapa de fechamento de mina em caso de falha do operador continua não sendo contemplado. Garantias financeiras são as melhores ferramentas para se evitar o surgimento de minas abandonadas (APEC, 2018).

Em Minas Gerais, vários Projetos de Lei já tramitaram no legislativo visando estabelecer mecanismos de garantias financeiras, durante o processo de licenciamento ambiental, de empreendimentos de alto impacto ambiental (Almeida e Lima, 2008). Em julho de 2016, em decorrência do desastre da barragem de Fundão, o projeto de lei de iniciativa popular "Mar de Lama Nunca Mais" (PL no 3.695/2016) (Minas Gerais, 2016) colocou em pauta a obrigatoriedade de uma "caução ambiental" que garantisse recursos para o fechamento de barragens ou para a recuperação socioambiental. Este Projeto de Lei foi aprovado, após o rompimento da Barragem B-I da Vale em 25 de janeiro de 2019, via Lei Estadual no 23.291 de 25 de fevereiro de 2019 (Minas Gerais, 2019), que estabeleceu a Política Estadual de Segurança de Barragens. Esta lei trouxe o instrumento da "caução ambiental", obrigatório nos processos de licenciamento ambiental para novos empreendimentos ou para aqueles já instalados, com o propósito de garantir a recuperação socioambiental para casos de sinistro e para desativação da barragem.

Para definição das diretrizes e regras para cálculo e implementação da caução ambiental foi criado o "GT Caução Ambiental" pelo Decreto no 47.739/2019 e Resolução Conjunta SEMAD/FEAM no 2.784/2019. A regulamentação da caução se daria por ato normativo próprio, no prazo máximo de cento e oitenta dias contados da publicação do Decreto no 47.739/2019. Mesmo que a caução ambiental estabelecida pela Lei no 23.291/2019, esteja vinculado às estruturas de barramento de rejeitos de uma mineração, já se configura como um avanço na preocupação em se estabelecer garantias financeiras para o fechamento de minas ou de suas estruturas.

Além das exigências previstas na legislação mineira para o fechamento de minas, existem vários projetos e estudos da dinâmica da mineração no Estado e dos impactos do fechamento das minas nos territórios. Especificamente, sobre o fechamento de minas no 
Quadrilátero Ferrífero, diversos estudos têm sido publicados. Neto (2008) e Acciolly (2012) discorrem sobre o uso futuro das minas de Gongo Soco e Águas Claras, respectivamente, Ruchkys (2007) e Ruchkys e Machado (2013) chamam a atenção para os sítios históricos da mineração e experiências de requalificação, Castro e Paula (2015) trazem uma metodologia para inventariar locais de interesse geológico e mineiro para fins turísticos. Em outras regiões do Estado, também ocorrem trabalhos desse cunho, como o de Lopes e Ruchkys (2015) no sul do estado, que realizaram uma modelagem de cenários integrados com foco nas minas inativas; Liccardo (2007) traz uma proposta de roteiro turístico para valorizar o patrimônio gemológico na região nordeste do estado e Barbosa et al. (2018) uma alternativa de turismo para minas órfãs de Ouro Preto. Experiências de novo uso de minas desativadas também são testemunhadas como a mina de Passagem, em Mariana, que atualmente é utilizada para fins turísticos. Em Brumadinho, o Instituto Inhotim, em antiga mina de ferro, apresenta um relevante acervo de arte contemporânea e espécies botânicas, utilizados para atividades socioeducativas. Na capital mineira, a área onde se situa o estacionamento Sul e as praças das Águas e do Britador, no Parque das Mangabeiras, pertenceu na década de 1960 à Mineração Ferrobel.

\section{Conclusões}

Este artigo avalia o quadro normativo da legislação brasileira, em especial do Estado de Minas Gerais, sobre o fechamento de minas e diretrizes para a gestão de minas abandonadas. Conforme verificado, o quadro constitucional e jurídico brasileiro avançou nos últimos anos, com o estabelecimento da etapa de fechamento de mina no Código de Minas e na modernização da legislação sobre o tema no Estado de Minas Gerais.

Entretanto, a análise realizada neste artigo demonstra, que apesar dos avanços, existe, ainda, nas legislações federal e estadual uma lacuna quanto às minas abandonadas. Ambas as legislações são omissas neste caso, pois operam no pressuposto de que irá existir uma pessoa responsável, a quem os reguladores podem impor obrigações e, se necessário, responsabilidade para recuperar a degradação causada pela atividade minerária. Implicitamente, sob essas leis, uma mina abandonada, que por definição não tem pessoa responsável sobre a qual os órgãos podem impor obrigações, presume-se que não ocorre. Consequentemente, essas leis não se aplicam, ficando para o Estado o papel de solucionar o problema.

Entretanto, mesmo com os avanços na legislação, ainda é incipiente no Brasil, a existência de um efetivo e adequado processo para o fechamento de mina, para tratar da questão de minas abandonadas e para coibir o surgimento de novas. Portanto, é fundamental que os órgãos ambientais e de regulação mineral estabeleçam e executem políticas de modo a fazer cumprir as leis existentes. Estado.

A regulamentação sobre fechamento de mina está longe de estar completa no

\section{Conflito de interesses}

Os autores declaram não haver conflitos de interesse.

\section{Referências}

Accioly, S. M. L. Uso futuro de áreas mineradas e o meio urbano: o caso de Águas Claras. Belo Horizonte: Universidade Federal de Minas Gerais, 2012. (Dissertação de mestrado). 
AGSA - Auditor-General of South Africa. Report of the Auditor-General to parliament on a performance audit of the rehabilitation of abandoned mines at the Department of Minerals and Energy, South Africa. Pretoria: AGSA, 2009. Disponível em: <http://cer.org.za/wp-content/uploads/2011/10/AG_Report_on_ abandoned_mines-Oct2009.pdf>. Acesso em: 12 abr. 2020.

Almeida, M. R.; Lima, H. M. Garantia financeira para fins de fechamento de mina e o seu impacto na viabilidade de uma mina. Estudo de caso de uma mina de grande porte. Revista da Escola de Minas, v. 61, p. 203-209, 2008.

ANM - Agência Nacional de Mineração. Anuário Mineral Brasileiro: principais substâncias metálicas 2018, Ano Base 2017. 2019. Disponível em: <http://www.anm.gov.br/ dnpm/publicacoes/serie-estatisticas-eeconomia-mineral/anuario-mineral/anuariomineral-brasileiro/amb_2018.pdf>. Acesso em: 20 jun. 2020.

APEC - Asia-Pacific Economic Cooperation. Mine closure checklist for governments. APEC Mining Task Force. 2018. Disponível em: <https://www.apec.org/Publications/2018/03/ Mine-Closure-Checklist-for-Governments>. Acesso em: 06 maio 2019.

Araújo, E. R. Fechamento de minas no Brasil não tem legislação federal específica e coloca em risco o ambiente e populações locais. Rio de Janeiro: CETEM/MCTI, 2015. Disponível em: <http://verbetes.cetem.gov.br/verbetes/Texto.aspx?p=9\&s=4>. Acesso em: 06 maio 2019.

Barbosa, V. S. B.; Lima, H. M.; Laudares, S.; Fonseca, B. M. Mine closure in Ouro Preto: The remnants of the 18th century gold rush and the tourism as an economic opportunity. International Engineering Journal, v. 72, n. 1, p. 39-46, 2019.

Bennett, K. Abandoned mines: Environmental, social and economic challenges. In: Fourie, A. B.; Tibbett, M. (Eds.). Proceedings of the 11th International Conference on Mine Closure. Australian Centre for Geomechanics, Perth, p. 241-252, 2016. Disponível em: <https://papers.acg.uwa.edu.au/p/1608_16_Bennett/>. Acesso em: 16 jan. 2020.

Brasil. Constituição da República Federativa do Brasil de 1988. Disponível em: <http://www.planalto.gov.br/ccivil_03/constituicao/ConstituicaoCompilado.htm>.

Acesso em: 20 out. 2019.

Brasil. Decreto no 24.642, de 10 de julho de 1934. Decreta o Codigo de Minas. Disponível em: <http://www.planalto.gov.br/ccivil_03/decreto/1930-1949/D24642 impressao.htm>. Acesso em: 20 out. 2020.

Brasil. Decreto-Lei no 1.985, de 29 de março de 1940. Código de Minas. Disponível em: <http://www.planalto.gov.br/ccivil_03/Decreto-Lei/1937-1946/Del1985.htm>. Acesso em: 20 out. 2020.

Brasil. Decreto-Lei no 227, de 28 de fevereiro de 1967. Código de Minas. Disponível em: <http://www.planalto.gov.br/ccivil_03/decreto-lei/del0227.htm>. Acesso em: 21 nov. 2018.

Brasil. Lei no 6.938, de 31 de agosto de 1981. Dispõe sobre a Política Nacional do Meio Ambiente, seus fins e mecanismos de formulação e aplicação, e dá outras providências. Disponível em: <http://www.planalto.gov.br/ccivil_03/leis/l6938.htm>. Acesso em: 21 nov. 2018.

Brasil. Decreto no 97.632, de 10 de abril de 1989. Dispõe sobre a regulamentação do artigo $2^{\circ}$, inciso VIII, da Lei no 6.938 , de 31 de agosto de 1981, e dá outras providências. Disponível em: <https://www2.camara.leg.br/legin/fed/decret/1989/decreto-97632-10abril-1989-448270-norma-pe.html>. Acesso em: 21 nov. 2018. 
Brasil. Lei no 7.805, de 18 de julho de 1989. Altera o Decreto-Lei $n=227$, de 28 de fevereiro de 1967, cria o regime de permissão de lavra garimpeira, extingue o regime de matrícula, e dá outras providências. Disponível em: <http://www.planalto.gov.br/ ccivil_03/LEIS/L7805.htm>. Acesso em: 24 nov. 2018.

Brasil. Lei no 9.605, de 12 de fevereiro de 1998. Prevê sanções penais para os crimes contra o meio ambiente, contra a Administração Pública e o Patrimônio Cultural, além de incentivar a cooperação internacional nas questões ambientais. Disponível em: <http://www.planalto.gov.br/ccivil_03/leis/19605.htm>. Acesso em: 24 nov. 2018.

Brasil. Plano Nacional de Mineração 2030. Brasília: Ministério de Minas e Energia, 2011. Disponível em: <http://antigo.mme.gov.br/web/guest/secretarias/geologia-mineracao-etransformacao-mineral/destaques-do-setor-de-energia/plano-nacional-de-mineracao2030>. Acesso em: 20 out. 2019.

Brasil. Decreto no 9.406, de 12 de junho de 2018. Regulamenta o Decreto-Lei no 227, de 28 de fevereiro de 1967, a Lei no 6.567, de 24 de setembro de 1978, a Lei no 7.805, de 18 de julho de 1989, e a Lei no 13.575, de 26 de dezembro de 2017. Disponível em: <http://www.planalto.gov.br/ccivil_03/_ato2015-2018/2018/decreto/D9406.htm>.

Acesso em: 20 out. 2019.

Brasil. Portaria DNPM no 237, de 18 de outubro de 2001. Institui Normas Reguladoras de Mineração. Disponível em: <http://www.dnpm-pe.gov.br/Legisla/Port_237_01.htm>. Acesso em: 28 nov. 2018.

Carvalho, E.; Diamantino, C.; Pinto, R. Environmental remediation of abandoned mines in Portugal: Balance of 15 years of activity and new perspectives. In: Drebenstedt, C.; Paul, M. IMWA 2016 - Mining Meets Water: Conflicts and solutions. Freiberg, Germany, 2016. p. 554-561.

Castro, P. T. A.; Paula, S. F. Geomorfologia antropogênica em função da mineração de ouro no século XVIII: Bases científicas e educativas na proposição de uma Trilha Geoturística Urbana na Sede no Município de Outro Preto (MG). Revista de Ecoturismo, v. 8, n. 4, p. 432-443, 2015.

Centeno, C. L. Sistematização de procedimentos para o fechamento temporário de minas de agregados. Porto Alegre: Universidade Federal do Rio Grande do Sul, 2017. (Dissertação de mestrado).

DGEG - Direcção Geral de Energia e Geologia. A herança das minas abandonadas: o enquadramento e a actuação em Portugal. 2011. Disponível em: <http://ec.europa.eu/ environment/waste/mining/pdf/Appendix_III_to_Annex3.pdf>. Acesso em: 26 jan. 2019.

Eustáquio Neto, S. Avaliação mínero-geoambiental da mina de Gongo Soco para fins de descomissionamento: propostas. Ouro Preto: Universidade Federal de Ouro Preto, 2008. (Dissertação de mestrado).

FEAM - Fundação Estadual do Meio Ambiente. I Cadastro de Minas Paralisadas e Abandonadas do Estado de Minas Gerais. Belo Horizonte: FEAM, 2016. Disponível em: <http://feam.br/images/stories/2016/AREAS_DEGRADADAS/Cadastro_Minas_Paralisada s_e_Abandonadas_2016l.pdf>. Acesso em: 21 nov. 2018.

Flores, J.; Lima, H. Fechamento de mina: aspectos técnicos, jurídicos e socioambientais. Ouro Preto: Editora UFOP, 2012.

González, R.A.M. Design of methodology for the identification of mining environmental liabilities in Colombia. Colômbia: Universidade Nacional da Colômbia. 2008. (Dissertação de mestrado). 
ICMM - International Council on Mining \& Metals. Guidance paper: Financial assurance for mine closure and reclamation. London: ICMM, 2006. Disponível em: <http://www.icmm.com/en-gb/publications/unpublished-pages/mine-closure/guidancepaper-financial-assurance-for-mine-closure-and-reclamation Acesso em: 21 nov. 2018.

ICMM - International Council on Mining \& Metals. Planning for integrated mine closure: Toolkit. London: ICMM, 2008. Disponível em: <http://www.ibram.org.br/ sites/700/784/00001524.pdf>. Acesso em: 21 nov. 2018.

Liccardo, A. Turismo mineral em Minas Gerais, Brasil. Global Tourism, v. 3, n. 2. 2007.

Lopes, C.; Ruchkys, U. Recursos da geodiversidade de São Thomé das Letras-MG e seu uso para mineração e geoconservação: perspectivas para a reconversão desse território mineiro. Desenvolvimento e Meio Ambiente, v. 35, p.335-347, 2015. https://doi.org/10.5380/dma.v35i0.41093

McCullough, C. D. Key mine closure lessons still to be learned. Proceedings of the International Mine Closure 2016 Congress, Perth, Australia, 2016.

MCMPR - Ministerial Council on Mineral and Petroleum Resources; MCA - Minerals Council of Australia. Strategic framework for managing abandoned mines in the minerals industry. Sydney: MCMPR/MCA, 2010. Disponível em: <https://archive.industry.gov.au/ resource/Mining/Documents/StrategicFrameworkforManagingAbandonedMines.pdf>.

Acesso em: 12 fev. 2019.

Mhlongo, S. E.; Amponsah-Dacosta, F. A review of problems and solutions of abandoned mines in South Africa. International Journal of Mining, Reclamation and Environment, v. 30, n. 4, p. 279-294, 2015. https://doi.org/10.1080/17480930.2015.1044046

Miller, C. G. Financial assurance for mine closure and reclamation: A report. Ottawa: International Council on Mining and Metals, 2005.

Minas Gerais. Decreto no 47.383, de 2 de março de 2018. Estabelece normas para licenciamento ambiental, tipifica e classifica infrações às normas de proteção ao meio ambiente e aos recursos hídricos e estabelece procedimentos administrativos de fiscalização e aplicação das penalidades. Disponível em: <https://www.almg.gov.br/ consulte/legislacao $/$ completa/completa.html?tipo $=$ DEC \&num $=47383 \&$ comp $=\& a n o=2018$ >. Acesso em: 12 fev. 2020.

Minas Gerais. Deliberação COPAM Normativa no 127, de 27 novembro 2008. Estabelece diretrizes e procedimentos para avaliação ambiental da fase de fechamento de mina. Disponível em: <http://www.siam.mg.gov.br/sla/download.pdf?idNorma=8732>. Acesso em: 12 fev. 2020.

Minas Gerais. Deliberação Normativa COPAM no 220, de 21 de março de 2018. Estabelece diretrizes e procedimentos para a paralisação temporária da atividade minerária e o fechamento de mina, estabelece critérios para elaboração e apresentação do relatório de paralização da atividade minerária, do plano de recuperação de áreas degradadas (PRAD) e do plano ambiental de fechamento de mina (PAFEM) e dá outras providências. Disponível em: <http://www.siam.mg.gov.br/sla/download.pdf? idNorma $=45938>$. Acesso em: 12 fev. 2020.

Minas Gerais. Lei no 23.291, de 25 de fevereiro de 2019. Institui a política estadual de segurança de barragens. Disponível em: <https://www.almg.gov.br/consulte/legislacao/ completa/completa.html?tipo=LEI\&num=23291\&comp=\&ano=2019>. Acesso em: $12 \mathrm{fev}$. 2020. 
Minas Gerais. Projeto de Lei (PL) 3.676/16 - Dispõe sobre o licenciamento ambiental e a fiscalização de barragens no Estado. 2016. Disponível em: <https://www.almg.gov.br/ sala_imprensa/proposicoes_de_repercussao/PL_3676_2016/index.html>. Acesso em: 20 maio 2020.

Neri, A. C. Tratamento de incertezas no planejamento do fechamento de mina. São Paulo: Universidade de São Paulo, 2013. (Tese de doutorado).

NOAMI - National Orphaned/Abandoned Mines Iniative. Guidelines for legislative review. 2010. Disponível em: <http://www.abandoned-mines.org/publications-e.htm>. Acesso em: 12 mar. 2019.

NOAMI - National Orphaned/Abandoned Mines Iniative. NOAMI performance uptade 2009-2015. 2015. Disponível em: <https://www.abandoned-mines.org/en/noamiperformance-update-2009-2015/>. Acesso em: 23 fev. 2019.

Oblasser, Á.; Chaparro, E. Estudio comparativo de la gestión de los pasivos ambientales mineros en Bolivia, Chile, Perú y Estados Unidos. Santiago de Chile: CEPAL, 2008. (Serie Recursos Naturales e Infraestructura, 131). Disponível em: <https://www.cepal.org/ es/publicaciones/6333-estudio-comparativo-la-gestion-pasivos-ambientales-minerosbolivia-chile-peru>. Acesso em: 12 mar. 2019.

Poveda, E. P. R. A eficácia legal na desativação de empreendimentos minerários. São Paulo: Signus, 2007.

Resende, A. G.; Lima, H. M. Análise das concessões de lavra quanto às suspensões temporárias de operação. Revista Escola de Minas, v. 62, n. 4, p. 539-544, 2009. https://doi.org/10.1590/S0370-44672009000400019

Resende, A. G.; Lima, H. M.; Flores, J. C. C. Análise do plano de fechamento de mina no plano de aproveitamento econômico de uma jazida: uma exigência da NRM-20. Revista Escola de Minas, v. 63, p. 685-690, 2010. https://doi.org/10.1590/S0370-44672010000400014

Ruchkys, U. A. Patrimônio geológico e geoconservação no Quadrilátero Ferrífero, Minas Gerais: potencial para a criação de um geoparque da UNESCO. Belo Horizonte: Universidade Federal de Minas Gerais, 2007. (Tese de doutorado).

Ruchkys, U.; Machado, M. M. M. Patrimônio geológico e Mineiro do Quadrilátero Ferrífero, Minas Gerais: caracterização e iniciativas de uso para educação e geoturismo. Boletim Paranaense de Geociências, v. 70, p. 120-133, 2013. https://doi.org/10.5380/ geo.v70i0.31541

Sampaio, J.; Rossi, C.; Pieri, B. Desativação de minas: considerações sobre a legislação brasileira frente a parâmetros internacionais. Revista Direito e Justiça: Reflexões Sociojurídicas, v. 20, n. 36, p. 43-70, 2019. https://doi.org/10.31512/rdj.v20i36.2766

Sanchez, L. E. Planejamento para o fechamento prematuro de minas. Revista Escola de $\begin{array}{lllll}\text { Minas, } & \text { v. } 64, & \text { n. } 1, & \text { p. } 117-124, & \text { 2011. https://doi.org/10.1590/S0370- }\end{array}$ 44672011000100016

Sanchez, L. E.; Silva Sanchez, S. S.; Neri, A. C. Guia para planejamento do fechamento de mina. Brasília: Instituto Brasileiro de Mineração, 2013.

SERNAGEOMIN - Servicio Nacional de Geología y Minería. Anuario de la Minería de Chile. Santiago de Chile: SERNAGEOMIN, 2020. Disponível em: <https://www.sernageomin.cl/ wp-content/uploads/Anuarios/anuario_2019_act231120.pdf>. Acesso em: 12 jul. 2020. 
SERNAGEOMIN - Servicio Nacional de Geología y Mineria. Catastro de faenas mineras abandonadas o paralizadas y análisis preliminar de riesgo. SERNAGEOMIN: Santiago de Chile: 2007. Disponível em: <http://sitiohistorico.sernageomin.cl/pdf/mineria/ cierrefaena/07.CatastroFaenasMineras2007.pdf>. Acesso em: 10 nov. 2018.

Sotomayor Cabrera, A. Remediación de pasivos ambientales mineros como estrategia para el cuidado del ambiente. Anales da Conferencia Académica Anual del Consorcio de Consorcio de Universidades, Lima, p. 81-90, 2016.

Taveira, A. L.S. Provisão de recursos financeiros para o fechamento em empreendimentos minerários. São Paulo: Escola Politécnica da USP, 2003. (Tese de doutorado).

Tonidandel, R. P.; Parizzi, M. G.; Lima, H. M. Aspectos legais e ambientais sobre fechamento de mina, com ênfase no Estado de Minas Gerais. Geonomos, v. 20, n. 1, p. 32-40, 2012. https://doi.org/10.18285/geonomos.v20i1.24

UNEP - United Nations Environment Programme. Abandoned mines: Problems, issues and policy challenges for decision makers. Procedings of the First Pan-American Worksop on Abandoned Mines, Santiago, Chile, 2001. Disponível em: <http://www.mineralresourcesforum.org>. Acesso em: 12 nov. 2019.

Unger, C. Legacy issues and abandoned mines. In: O'Callaghan, T.; Graetz, G. (Eds.). Mining in the Asia-Pacific. Cham: Springer, 2017. https://doi.org/10.1007/978-3-319-613956_20

Unger, C.; Lechner, A.; Kenway, J.; Glenn, V.; Walton, A. A jurisdictional maturity model for risk management, accountability and continual improvement of abandoned mine remediation programs. Resources Policy, v. 43, p. 1-10, 2014. https://doi.org/10.1016/ j.resourpol.2014.10.008

Worrall, R.; Neil, D.; Brereton, D.; Mulligan, D. Towards a sustainability criteria and indicators framework for legacy mine land. Journal of Cleaner Production, v. 17, n. 16, p. 1426-1434, 2009. https://doi.org/10.1016/j.jclepro.2009.04.013

Informação da Licença: Este é um artigo Open Access distribuído sob os termos da Licença Creative Commons Attribution, que permite uso irrestrito, distribuição e reprodução em qualquer meio, desde que a obra original seja devidamente citada. 